\title{
El desembarco de Bayo en Mallorca según las cartas del periodista Gabriel Fuster Mayans 'Gafim'
}

\author{
Manuel Aguilera Povedano \\ CESAG - Universidad Pontificia Comillas \\ maguilera@cesag.org
}

Recibido: 6 de enero de 2015

Aceptado: 31 de mayo de 2015

\begin{abstract}
Resumen
El popular periodista mallorquín y concejal del Ayuntamiento de Palma Gabriel Fuster Mayans, alias Gafim, luchó con sólo 23 años en las filas del bando nacional durante la Guerra Civil Española. Gracias a las cartas inéditas que escribió a su novia, el autor ha podido reconstruir su papel durante el desembarco de Bayo en agosto-septiembre de 1936. Un testimonio excepcional de quien se convertiría en uno de los personajes más ilustres de la capital balear.
\end{abstract}

Palabras clave: Gabriel Fuster Mayans; Gafim; Desembarco de Bayo; Guerra Civil Española; Periodismo; Mallorca; Islas Baleares

\section{The landing of Commander Bayo in Majorca through the letters of journalist Gabriel Fuster Mayans 'Gafim'}

\begin{abstract}
The well-known Majorcan journalist and town councillor in Palma Gabriel Fuster Mayans, alias Gafim, fought in the ranks of the national side during the Spanish Civil War when he was only 23. Using unpublished letters to his bride, the author has been able to retrace his role during the landing of the ship under the command of captain Bayo in August 1936, an exceptional witness from a man who became one of the most distinguished public figures in the Balearic capital.
\end{abstract}

Key words: Gabriel Fuster Mayans; Gafim; Bayo landing; Spanish Civil War, Journalism; Mallorca; Balearic Islands.

\section{Referencia normalizada}

Aguilera Povedano, M. (2015). El desembarco de Bayo en Mallorca según las cartas del periodista Gabriel Fuster Mayans "Gafim”. Historia y Comunicación Social. Vol 20, número 1, páginas 45-65.

Sumario: 1. Introducción. 2. El periodista. 3. El militar. 4. La guerra a través de las cartas de Gafim. 5. Después de la batalla. 6. Conclusiones. 7. Referencias bibliográficas. 


\section{Introducción}

Gabriel Fuster Mayans, alias Gafim (Palma, 1913-1977), es uno de los periodistas más ilustres de Mallorca. Escribió durante más de 40 años en el diario Baleares, el más importante de la época, y sus columnas eran de las más leídas. También fue concejal de Cultura del Ayuntamiento de Palma y, como tal, creó los ya tradicionales premios literarios Ciutat de Palma. En 1979, el consistorio le dedicó un busto medio relieve que todavía se puede admirar en una las columnas principales de la Plaza Mayor de la ciudad ${ }^{1}$.

Para conocerle está su inmensa obra periodística y su único libro, Tres viatges en calma per l'illa de la calma, que se publicó en 1952. Sin embargo, desde 1999 existe una amplia biografía escrita por Carles Marín. En ella se descubre a una Gafim en todas sus facetas: la familiar, la política, la periodística y, también, la militar. Marín recoge el papel que tuvo el periodista en la Guerra Civil Española, la cual le sorprendió con 23 años y le llevó a luchar en las filas nacionales contra los milicianos del comandante republicano Alberto Bayo en agosto de 1936. En la biografía aparecen extractos de las cartas que escribió a sus padres desde el frente pero ahora, en este artículo, sacamos a la luz las 18 cartas que escribió a su novia, Maria Antònia Sureda Sancho, donde es más explícito respecto a los avatares de la guerra. Como el propio Gafim explica, a ella le contaba cosas que omitía a sus padres: "Todo lo que te digo es verdad, a ti te lo puedo decir porque sé que te lo tomas con serenidad"2. El periodista acierta de manera milimétrica al dar datos y fechas. Por ello, el relato goza de credibilidad.

Además de las cartas a sus padres que hizo públicas Carles Marín, otros autores han publicado correspondencia de Gafim con literatos como Miquel Villalonga y Salvador Espriu. Todas ellas sirven para conocer a la persona y al periodista pero no al militar porque el tema guerra civil apenas se tocó ${ }^{3}$.

En este artículo reconstruiremos a través de los ojos de Gafim las primeras semanas de la guerra civil en Palma así como la batalla del desembarco de Bayo, la cual duró del 16 de agosto al 4 de septiembre de 1936. Como decimos, contaremos como novedad con 18 cartas que escribió a su novia entre el 23 de julio y el 10 de septiembre, y se completará con lo ya publicado en su biografía, basado sobre todo en cinco cartas a sus padres. El contexto lo aportaremos a través de las principales obras sobre el desembarco de Bayo hechas por Massot i Muntaner, Martínez Bande, Mascaró Pasarius, Manuel Cruells, Miguel Durán, Antoni Tugores y el propio Alberto Bayo. También utilizaremos prensa de la época (La Almudaina, El Día y Arriba) y actual (Diario de Mallorca, Última Hora y El Mundo / El Día de Baleares).

Respecto a las primeras semanas de la guerra, el relato se limita a hablar de los bombardeos que sufre la isla, así que compararemos los datos con la obra Els bombardeigs de Mallorca durant la Guerra Civil, de Massot i Muntaner, el cual usa fuentes fiables como los informes de la Defensa Antiaérea Activa de Palma. Antes, conoceremos a Gafim gracias a sus propios escritos y a los trabajos de investigación de Carles 
Marín, Sebastià Arrom, Margalida Socías, Josep Maria Buades, Damià Ferrà-Ponç, Catalina Amer y Gaspar Sabater.

\section{El periodista}

La madre de Gafim, Margalida Mayans, era ibicenca y su padre, Gabriel Fuster, palmesano. Su apellido, Fuster, es de origen xueta, es decir, judío converso ${ }^{4}$. Gafim estudió Derecho en la Universidad de Barcelona, donde entabló estrecha amistad con los poetas Bartomeu Rosselló-Pòrcel y Salvador Espriu. Acabó la carrera en la Universidad Zaragoza y volvió a Palma el verano de 1934 para preparar las oposiciones a notario 5 .

La carrera periodística de Gafim comenzó en ese momento, con tan sólo 21 años, mediante colaboraciones puntuales en la revista local Brisas. Tras el paréntesis de la guerra, en 1941 decidió abandonar las oposiciones a notario y siguió con trabajos esporádicos como periodista. Su amigo Miquel Villalonga, hermano del célebre Llorenç, le hacía de consejero en el arte de la redacción: "Tus escritos me parecen bien y me asombra ver que mejoran con una celeridad desusada. En menos de un mes has recorrido un camino de 10 años"6. Gafim se convirtió en colaborador de arte y cultura en el Baleares, diario portavoz del Movimiento Nacional y rotativo más leído en Mallorca. De forma paralela, su compromiso con el franquismo fue en aumento. En 1943 ingresó en Falange y recibió la medalla de la Vieja Guardia. En 1952 fue nombrado miembro de la Junta Provincial de la Vieja Guardia de Baleares?

Sobre su ideología, Massot i Muntaner dice que era "de clara significación derechista". Josep Buades también apunta que se decantó por el bando de Franco "por plena convicción de ideas". Ferrà-Ponç dice que entró en Falange porque temía que los socialistas le quitaran la finca familiar ${ }^{10}$. En cualquier caso, era un gran impulsor de la tradición cultural mallorquina e introdujo el idioma catalán en sus artículos desde los años cincuenta ${ }^{11}$.

Dio el salto a la política en 1951. Ese año fue nombrado regidor de Cultura, Deportes y Jardines del Ayuntamiento de Palma. Duró cinco años y una de sus labores más recordadas es la creación en 1954 de los premios literarios "Ciutat de Palma", los cuales perduran todavía hoy, 60 años después ${ }^{12}$.

Gafim se mantuvo fiel al diario Baleares pero a la vez colaboró con todo tipo de revistas y periódicos. Para obtener el carnet oficial de periodista, en 1952 realizó un curso intensivo en la Escuela Oficial de Periodismo en Madrid, donde coincidió con Pere A. Serra, actual presidente del Grupo Serra, primer grupo mediático de Baleares. Aquello le sirvió para obtener su licencia y ascender en el Baleares a redactor de primera $^{13}$.

Su columna titulada "Tertulia en la Plaza Mayor" se publicó diariamente, salvo los domingos, durante 20 años, desde 1957 a 1977. En esta sección escribía de todos 
los temas, siempre con una frescura y amenidad excepcionales, por eso se convirtió en uno de los autores más leídos de la isla ${ }^{14}$. En 1964 fue nombrado director de la revista Lluc y entre 1969 y 1973 ocupó la presidencia de la Asociación de la Prensa de Baleares.

\section{El militar}

Cuando estalló la guerra, el 18 de julio de 1936, tenía sólo 23 años y era un palmesano con novia en la otra punta de la isla, Artá. Aquel día, Mallorca se mantuvo todavía republicana debido a la actitud expectante del comandante general Manuel Goded. Al día siguiente, 19 de julio, tropas regulares y falangistas ocuparon los puntos neurálgicos de Palma y emitieron el bando de guerra de adhesión de las Baleares a la sublevación militar. Salvo algún tiroteo aislado, no hubo incidentes importantes, así que Goded cedió el mando al teniente coronel de Ingenieros Luis García Ruiz y se trasladó a Barcelona donde encontraría la derrota y la muerte ${ }^{15}$.

Al final, la única isla balear que quedó fiel a la República fue Menorca. Con todo el levante español en manos también republicanas, Mallorca sufrió varios bombardeos durante las primeras semanas sin tener margen alguno para la respuesta. Sólo en el primer mes de guerra, Palma fue bombardeada por aviones republicanos en 24 ocasiones. Los principales objetivos eran los buques de guerra anclados en los puertos y las dependencias militares, pero también arrojaron bombas indiscriminadamente sobre la población porque, según Gafim, los aviones volaban a "gran altura"16 para protegerse de las defensas antiaéreas, así que erraban el tiro. Al final de la contienda, más de 150 baleares murieron bajo el efecto de las bombas. Entre ellos había 35 niños ${ }^{17}$.

Gafim ya había hecho el servicio militar así que fue movilizado en los primeros días. Entró como alférez provisional en el cuartel de artillería de San Pedro, situado donde hoy está Es Baluard, frente al puerto de Palma -hoy club náutico-. Su guerra de verdad empezó el 21 de julio, cuando al patrullar en camioneta por el barrio de Santa Catalina el vehículo recibió un disparo que no causó daños personales.

A partir del día 23, las cartas de Gafim relatan los bombardeos sobre Palma y detallan con cierta precisión dónde caen las bombas y si han causado víctimas. Desde la azotea del edificio tenía una panorámica perfecta de lo que ocurría en la ciudad. Incluso estuvo al cargo de la ametralladora antiaérea ${ }^{18}$.

La llamada "Columna Baleares" del capitán republicano Alberto Bayo llegó a Mallorca el 16 de agosto de 1936 después de parar en Menorca y conquistar Ibiza, Formentera y Cabrera. Estaba formada por personas de muy diferente condición que degeneró en una desorganización e indisciplina totalmente suicida. Pensaban que la toma de Mallorca sería un paseo militar. Diferían en ideología y la mayoría no tenía instrucción militar. En total, comparando diferentes fuentes, desembarcaron unos 8.000 milicianos antifascistas. En cuanto al bando contrario, según Durán, no hubo 
en el frente de Manacor más de 2.886 soldados nacionales, alrededor de tres veces menos efectivos que el bando enemigo ${ }^{19}$.

Gabriel Fuster fue al frente el mismo día del desembarco, el 16 de agosto, donde pasó dos días y luego volvió a Palma a descansar. El día 20 se trasladó definitivamente a Manacor, el pueblo de retaguardia más próximo al frente. No abandonó la línea de fuego hasta terminar el combate y libraría las batallas más decisivas del desembarco.

\section{La guerra a través de las cartas de Gafim}

La primera carta que escribió una vez comenzado el conflicto data del 23 de julio. En ella habla del primer bombardeo que sufrió la isla ${ }^{20}$. A continuación, reproduciremos sólo el texto que tiene que ver con el conflicto armado. Se ha eliminado lo privado e irrelevante. Las aportaciones del autor del artículo están entre corchetes. Después de cada carta se revisan los datos según el resto de fuentes.

Carta a su novia el 23 de julio de 1936 (cuartel de artillería de San Pedro -hoy Es Baluard-)

Queridísima: te escribo desde el cuartel de S.P. [San Pedro] (...)

Esta mañana se ha presentado un avión enemigo. Ha arrojado tres bombas y proclamas invitando a los soldados a la rebelión contra los jefes y oficiales. Se ha hecho nutridísimo fuego de fusil y ametralladora y ha caído cerca de Sóller.

(...) Palma se ha ido despoblando rápidamente, la gente huye temerosa de un nuevo ataque y bombardeo más eficaz pues las bombas han caído al mar. Por la calle sólo se ven soldados y fascistas armados de fusil.

Anteayer noche estuve patrullando en un camión con un cabo y seis soldados por Santa Catalina y cerca de las 2.30 de la madrugada nos pegaron dos tiros a los que contestamos en debida forma pero no vimos a nadie, sólo vimos fogonazos. Una bala dio en el camión pero afortunadamente no pasó nada más. (...) Biel

En general, los datos coinciden con el resto de fuentes. El lanzamiento de octavillas aparece en Massot i Muntaner. Eran proclamas dirigidas a la tropa para que se rebelara y entregara la ciudad en 24 horas $^{21}$. Respecto a que el avión cayó en Sóller, el testigo Patrick Laureau coincide en que fue tocado por las ametralladoras. El piloto resultó herido y tuvo que amerizar de emergencia ${ }^{22}$.

Carta a su novia el 28 de julio de 1936 (cuartel de San Pedro)

Queridísima: (...) fijate, ayer pasó otro avión (anteayer, tres) y yo salí al terrado con la pistola y le pegué nueve tiros, y cuando se terminaron le tiré la pistola con una rabia. (...)

Las noticias que se reciben son pocas pero buenas (...) 
Noticia: ayer un avión tiró una bomba encima de casa de (espántate) Francisco Salvá, (...) no han ocurrido desgracias personales afortunadamente pues los dormitorios están al otro lado de la casa. ijImagínate doña Isabel Font las cosas que debe contar!! Esa bomba iba dirigida a Capitanía. Son unos moletas esos aviadores, no saben tirar. El otro día cayó otra bomba cerca del frontón que iba para [el cuartel de] San Pedro, ison unos moletas! Como vuelan a gran altura por miedo a nuestro tiros no dan en el blanco nunca y pagan justos por pecadores.

(...) Biel.

Los datos vuelven a coincidir totalmente con Massot. El 26 de julio hubo "tres bombardeos, uno hecho por dos aparatos y los otros por uno solo, con un total de 26 bombas y cuatro edificios totalmente destruidos" ${ }^{23}$. Y, efectivamente, el 27 de julio pasó solo un Savoia-62 (S-1) que derribó parcialmente dos edificios ${ }^{24}$.

Carta a su novia el 1 de agosto de 1936 (cuartel de San Pedro)

Queridísima: (...) La situación va mejorando de día en día. Los ataques aéreos empero se repiten todos los días. Supongo que ya sabrás que anteayer hubo varios muertos y bastantes heridos a consecuencia del bombardeo de dos aviones enemigos. (...) En todos hubo muertos y heridos porque la gente había tomado demasiada confianza y al oír un avión salían a la calle y en azoteas a contemplar sus evoluciones y claro, sucedió lo natural; pero ahora, siguiendo órdenes de la Comandancia Militar, al oír tocar la sirena se mete todo el mundo en sótanos y pisos bajos y así no se han tenido que lamentar desgracias.

Cuando acabe todo esto el comandante me ha dicho que me necesitaba para hacer "limpieza", a lo mejor iré de servicio a Capdepera [nordeste de Mallorca] (...)

(...) Un momento: ;iotro avión!! Perdona un momento, voy a salir.

No ha sido una avión, han sido dos. Han tirado no sé cuántas bombas y una de ellas ha caido detrás del cuartel, cerca del polvorín. No sé qué hubiese pasado si logra hacerlo estallar.

(...) Uno llega a acostumbrarse al peligro de tal modo que cuando no lo hay es terriblemente aburrido. (...) Biel.

$\mathrm{Su}$ novia le preguntó qué significaba eso de "limpieza" en Capdepera y en la siguiente carta él explica lo siguiente: "'limpieza' es ir por lo pueblos a buscar armas en individuos sospechosos y fichados, ¿comprendes?”. Sobre esto, Massot dice que "columnas de soldados recorrieron muchos pueblos de Mallorca y contribuyeron a organizar la vida municipal, a la vez que detenían a los elementos izquierdistas más destacados. En esta labor les ayudaron los pequeños grupos de falangistas locales"25.

Aunque hubo duros bombardeos del 28 al 30, se refiere concretamente al bombardeo del 28 de julio. Al decir "anteayer" no coinciden las fechas porque debió empezar a escribir la carta un día o dos antes de enviarla. La Defensa Antiaérea Activa de Palma informó que a las 12 horas dos Savoia-62 habían arrojado varias bombas que "cayeron en varias calles y plazas de esta ciudad, causando serios y numerosos 
desperfectos, en edificios, principalmente en casas de humildes obreros, ocasionando tres muertos y quince heridos" 26 .

En cuanto a los aviones que aparecen mientras escribe, el 31 de julio por la mañana volaron dos aviones, por la tarde fueron tres y el 1 de agosto sólo uno. Por ello, esta carta debió ser escrita el 31 de julio por la mañana, aunque lleve la fecha del 1 de agosto. Para levantar el ánimo de la población, el coronel Emilio Ramos Unamuno anunció en la prensa un premio de 5.000 pesetas "a quien derribe un avión comunista volando sobre Mallorca". Ese mismo día, primero de agosto, dos submarinos republicanos ocuparon Cabrera ${ }^{27}$.

Carta a su novia el 4 de agosto de 1936 (cuartel de San Pedro)

Queridísima: (...) Tenemos bombardeo diario pero ya estamos acostumbrados. Las noticias del movimiento son buenas, lo que se dice buenas. No creas en las patrañas que la gente de por ahi dice o piensa. Fíjate que la radio de Barcelona tuvo la cara de decir que Palma ardía por los cuatro costados y que la gente huía en lanchas. Lo bombardeos se reducen a cuatro desperfectos en las casas y si la gente se refugia en los sótanos y pisos bajos no hay peligro ninguno. (...) Biel

En las tres semanas previas al desembarco (16 de agosto) se bombardeó permanentemente Mallorca, tanto con proyectiles como con proclamas. El propio Bayo lo reconoce en sus memorias: "Les molesté incesantemente para desmoralizarlos y "ablandar su resistencia"28. El único día que hubo tranquilidad fue el 9 de agosto porque los hidroaviones estaban ocupados en la toma de Ibiza ${ }^{29}$.

Carta a su novia el 5 de agosto de 1936 (cuartel de San Pedro)

Queridísima: (...) Ayer y hoy vinieron dos aviones (uno hoy y otro ayer) y no han hecho más que tirar periódicos suyos que dicen que ellos lo tienen todo. Bomba ninguna. (...) Biel.

Coincide con el resto de fuentes. Los aviones venían de Menorca y sólo arrojaron periódicos. Eran ejemplares falsos del diario mallorquín La Almudaina -génesis del Diario de Mallorca- con sólo noticias de los avances republicanos. La cabecera auténtica, hecha en Mallorca, alertó el 5 de agosto de la maniobra enemiga. Según el periódico El Día, los ejemplares apócrifos decían que "las fuerzas del Frente Popular" se habían "apoderado de la isla de Cabrera y que van en ella, de población en población, en medio de aclamaciones" ${ }^{30}$. En Cabrera no había -ni hay- ninguna población, sólo una pequeña guarnición y unos pocos habitantes.

\section{Carta a su novia el 6 de agosto de 1936 (cuartel de San Pedro)}

Queridísima: (...) Creo que el domingo próximo, si la cosa no empeora, iremos una columna a Lluchmayor (sic), Campos, Porreres y Algaida para hacer un recorrido que levante un poco los ánimos de la gente. ;Lástima que no sea a Capdepera! El comandante me ha dicho que son muchos quilómetros para una jornada y para una columna de 200 hombres pero a la primera ocasión iremos. (...) Como hace 
mucho calor dentro del uniforme lo he suprimido y, como Ordinas y algún otro, voy con un mono azul con las insignias y el correaje. Queda muy bien, parecemos aviadores y es comodísimo y fresquísimo. (...) Los aviones vuelan todos los días pero han terminado las bombas. No creas nada de lo que digan. (...) Biel.

Como ya se ha apuntado, a partir del mes de julio se formaron pequeñas columnas mixtas de Infantería y Artillería que recorrieron los pueblos de Mallorca en misión de vigilancia y propaganda. El 6 de agosto, el coronel García Ruiz anunció en Radio Mallorca que el enemigo preparaba un desembarco. El día 9 ya había listas tres columnas motorizadas para actuar con rapidez ante el inminente desembarco enemigo ${ }^{31}$.

Carta a su novia el 7 de agosto de 1936 (cuartel de San Pedro)

Queridisima: (...) Ayer tuvimos un trabajo abrumador: se cargaron dos baterías para ir a Santanyí porque se temía un desembarco. Afortunadamente para ellos no han venido que si llegan a venir se la cargan. (...) Anteayer por la noche me la pasé en vela y la otra noche lo mismo y hoy estoy de guardia. (...) Biel.

El diario de operaciones del regimiento de Artillería dice que el 5 de agosto -no el 6, por lo que quizá Gafim escribió la carta un día antes- "salieron dos piezas de 10,5 en misión de vigilancia y seguridad motivada por alarma. Las baterías de montaña y ligera quedaron ya motorizadas permanentemente" ${ }^{32}$.

Carta a su novia el 8 de agosto de 1936 (cuartel de San Pedro)

Queridísima: (...) Ya ves, yo no puedo moverme del cuartel más que para ir a casa o cenar y mañana hace tres semanas que hago esta vida aburrida y espantosa. El peligro quita un poco de monotonía a esta vida, cuando lo hay, pero ahora, por ahora todo es una balsa de aceite. Dicen que hasta finales de este mes las cosas no marcharán. Créeme que estoy aburrido, malhumorado y ya tengo ganas de que acabe de una vez. (...) Biel.

E1 7 de agosto había llegado la noticia de la ocupación de Formentera y la amenaza de la marina republicana sobre Ibiza, que caería el día 9. El desembarco en Mallorca era inminente, así que los militares tenían a todo el personal movilizado y alerta. El teniente coronel Luis García Ruiz llegó a pedir por radio que "cada habitante fuera un defensor, armándose en la forma que se pudiera, hasta con piedras y palos" 33 .

\section{Carta a su novia el 10 de agosto de 1936 (cuartel de San Pedro)}

Queridisima: (...) He ido al Círculo [Mallorquín] a cenar y te escribo desde alli. Hoy ha habido desfile y ha sido apoteósico: vivas a España, al ejército, a Falange, etc. Yo he hecho un gran papel de oficial ayudante detrás del comandante [Gerardo Martínez de Tejada] y delante de todo el mundo. (...)

Del continente hay pocas noticias pero todo va bien. El coronel Ramos [Emilio Ramos Unamuno ${ }^{34}$ ] (suegro de Pascual Ribot) (sic) vino al cuartel y nos echó un discurso que hizo llorar de emoción a muchos artilleros, entre ellos el comandante. (...) Biel. 
El desfile se celebró el domingo 9 de agosto y contó con alrededor de 1.000 soldados entre tropa regular, falangistas, requetés y milicianos de Acción Popular. Partieron de las Ramblas, pasaron por calle Unió, el Borne, subieron por Conquistador, Cort, calle Colom, Plaza Mayor, San Miguel y terminaron en Eusebio Estada. Encabezó el desfile el coronel Aurelio Díaz de Freijó y el gobernador civil teniente coronel Luis García Ruiz. Según el diario La Almudaina, el teniente coronel de Artillería Gerardo Martínez de Tejada dio el siguiente discurso: "La canalla que nos ha bombardeado en los días pasados se ha convencido de que nada puede lograr ante el brío y el entusiasmo de los mallorquines. Pero ya que la eficiencia militar de tales bombardeos es nula, ahora ha inventado la patraña de que vienen a desembarcar a Mallorca. ¡Soldados! ¡Milicianos! ¿Prometéis que si esa canalla viene a Mallorca sólo encontrará en ella su tumba? (¡Sí!, resonó)"35.

Carta a su novia el 11 de agosto de 1936 (cuartel de San Pedro)

Queridísima: (...) El otro día fui voluntario para ir a las ametralladoras del terrado que es de las cosas más emocionantes que hay. El teniente coronel [Martínez de Tejada] me felicitó delante de todo el mando. Te lo digo ahora porque ya no estaré más pues me he pasado a morteros, que son unos cañones de trinchera que tienen el tiro muy bueno. Por ejemplo: para tirar al enemigo que se encuentre detrás de una montaña. (...)

Si intentasen desembarcar en Mallorca, me gustaría que fuera cerca de Cala Ratjada, así nos veríamos. No te asustes si te dicen o si se dice que van a desembarcar, ojalá lo hagan y verán esos "rabassaires" como las gastan por aqui, jverán que hermosas ensaimadas se fabrican en la isla! Biel

Gafim se puso al mando de un grupo de morteros que, según Carles Marín, la poca experiencia provocó que el primer disparo les cayera prácticamente encima ${ }^{36}$.

Como se aprecia en la carta, todos los mallorquines estaban pendientes del desembarco. Bayo lanzó octavillas en Mallorca anunciando una operación a gran escala. Exageró descaradamente las cifras para infundir terror. Dijo que tenía "80 hidroaviones, 10 barcos de nuestra escuadra de guerra, 6.000 bombas de aviación que os pienso regalar, 8.000 incendiarias cuya muestra os haré ver hoy mismo, 5 submarinos y 10.000 hombres voluntarios". Su objetivo era que los soldados que defendían la isla se rebelaran o se echaran al monte. En la octavilla ponía el ejemplo de Ibiza, la cual se había tomado sin apenas resistencia: "Al vernos con un pie en la isla, se pasaron a nosotros casi todos los soldados" ${ }^{\prime 37}$.

\section{Carta a su novia el 14 de agosto de 1936 (cuartel de San Pedro)}

Queridísima: (...) Esta mañana he ido a Santanyí con el comandante a pasar una [ininteligible] inspección y hemos regresado a las 15.30. A las cuatro comía más muerto que vivo y esta tarde he estado trabajando con los morteros. Creo que mañana iremos a Torre d'en Pau [club militar de la bahía de Palma] a probarlos. Hoy hemos tenido la agradable visita de tres aviones por la mañana y otros tantos por la tarde. No ha habido desgracias pero sí en Santa María que han matado a una persona y herido gravemente a otra, en Lluchmayor (sic) han herido a tres más, etc. 
Hay que guardarse. Hay que guardarse cuando viene el avión [Esta última frase subrayada]. (...) Biel.

Sobre la expedición a Santanyí, Massot dice que un día antes, el 13, "salió hacia Campos", pueblo colindante a Santanyí, una compañía de infantería y una batería del 7,5 comandada por el capitán de Artillería retirado Sebastià Feliu ${ }^{38}$. Parece que esperaban que el desembarco fuera en la costa este, como así sería días después.

Respecto a las prácticas en Torre d'en Pau, se refiere a un club militar situado junto al mar dentro del municipio de Palma, en la zona de Cala Gamba ${ }^{39}$.

En cuanto a los bombardeos republicanos, Gafim vuelve a acertar de pleno. Ese día, según varias fuentes, atacaron la isla siete aviones que arrojaron alrededor de un centenar de bombas entre Palma, Santa María y Llucmajor. Causaron varios heridos y en Santa María la muerte instantánea del pagés Miquel Dolç Canyelles. Poco después moriría de las heridas un vecino de éste, Gabriel Vich ${ }^{40}$.

Carta a su novia el 15 de agosto de 1936 (cuartel de San Pedro)

Queridísima: (...) Hoy estoy de guardia y entre el teléfono y el movimiento del personal y la guardia me vuelven loco. (...) Hoy no hemos tenido, hasta ahora (son las 15.30) visita de aviones, veremos cómo termina el día. Ayer arrojaron 30 bombas, ¡treinta bombas! (;canallas!) y no causaron ninguna desgracia personal, esto es la demostración de que si se guardan todo bombardeo es inútil. La gente se va entrenando y ya no hay aquel pánico de los otros días. (...) Biel

Se refiere al mismo bombardeo de la anterior carta. Habla de 30 bombas sólo en la ciudad de Palma, aunque otras fuentes ascienden la cifra a 45. En total, como hemos dicho, se arrojó alrededor de un centenar en toda la isla. En Palma causaron "destrozos y heridos" pero no hubo que lamentar muertes. Las autoridades habían emprendido un ambicioso plan de adaptación de sótanos y construcción de refugios antiaéreos ${ }^{41}$.

El día siguiente, 16 de agosto, alrededor de 2.000 milicianos antifascistas desembarcaron en varios puntos de la costa este de Mallorca, en los municipios de Manacor y Sant Llorenç - ambos al norte de Santanyí-. La primera alerta la dio el capitán Ignacio Despujols, encargado de la vigilancia de la zona. La Comandancia de Palma recibió el aviso a las 5.30 de la madrugada. Despujols sólo contaba con 25 milicianos así que, tras agotar la munición contra los que desembarcaban en Porto Cristo (Manacor), se replegó hasta las Cuevas dels Hams, donde formó una línea defensiva con refuerzos de Manacor y Palma.

Los republicanos tomaron toda la línea de costa entre Porto Cristo y Son Servera. En lugar de aprovechar el factor sorpresa, se entretuvieron en los pequeños pueblos conquistados, dando al enemigo tiempo para organizarse. Mascaró Pasarius subraya la grave equivocación de Bayo: "Las victorias militares se alcanzan avanzando, llevando la iniciativa en el ataque, no atrincherándose y esperando los acontecimien- 
tos". Este error sumado al desorden e indisciplina de varias unidades, sobre todo las anarquistas, le costó a Bayo 422 bajas en una sola jornada ${ }^{42}$.

La columna donde estaba encuadrado Gafim, que dirigía Martínez de Tejada, salió a primera hora desde Palma pero dio un extraño rodeo que retrasó su llegada al frente hasta las 15.30 horas. Siguió el itinerario Campos-Felanitx y llegó a Portocolom, donde se creía que habían desembarcado algunas fuerzas pero no encontraron a nadie ${ }^{43}$. Volvió a Manacor y recibió la orden de marchar a las Cuevas dels Hams para reforzar la defensa en su flanco izquierdo, hacia el norte. Enseguida se enfrentó al enemigo y le hizo retroceder. El propio Martínez de Tejada resultó herido. Al día siguiente, 17 de agosto, la columna nacional del comandante Esquivias atacó por el franco derecho y tomó todo Porto Cristo salvo la zona alta que dominaba la casa Can Servera. Allí, los republicanos se hicieron inexpugnables a costa de grandes bajas. Bautizaron el lugar como "el parapeto de la muerte"44. Una vez organizada la defensa, Gafim pudo volver a descansar a Palma.

Carta a su novia el 18 de agosto de 1936 (cuartel de San Pedro)

Queridísima: estos días no te he escrito por la razón que tú ya puedes suponer. He estado dos días en la línea de fuego, los de casa no sabían nada, ni yo quise decir nada. Por fortuna, todo está terminado, estoy cansadísimo, hace cuatro días que no duermo nada, no me aguanto, de palabra te contaré muchas cosas, cosas emocionantes, no te lo escribo por no asustarte. Mi opinión es que os vayáis a la Tofona (sic) o a Palma porque no sé si sabrás que llegaron hasta Son Servera. (...) El comandante me ha felicitado, ya te contaré... Biel.

El 19 de agosto la batalla estaba todavía por decidir porque a pesar del éxito de la defensa nacional, los republicanos eran dueños del mar y del aire. Esto cambió la mañana de este día con la llegada desde Italia de tres hidros Savoia-80. Amerizaron en Pollença y poco después atacaron las posiciones republicanas. Su papel fue testimonial porque no volvieron a intervenir. A pesar de ello, el hecho supuso un impulso de moral para Gafim y sus compañeros ${ }^{45}$.

Carta a su novia el 20 de agosto de 1936 (cuartel de San Pedro)

Querida: seguramente hoy partiré otra vez hacia el frente. Mi pensamiento seguirá puesto en ti hasta el último aliento. No te preocupes pues ya queda poca cosa que hacer. Supongo que te habrás enterado de la llegada de nuestros aviones, de modo que será cuestión de pocos días. (...) Biel.

Al día siguiente envió una carta a sus padres que publicó su biógrafo Carles Marín en 1999, por lo que no es inédita. En ella explica que estaba en Manacor y formaba parte de una nueva columna.

\section{Carta a sus padres del 21 de agosto de 1936 (Manacor)}

Estoy en Manacor (...) La gente se desvive para servirnos y obsequiarnos, me he afeitado en una casa, me he lavado en otra y he desayunado en otra. En el frente no 
hay más que unos tiroteos aislados. Hemos llegado a ser una columna de más de 400 hombres: morteros, ametralladoras, enfermeros e intendencias. Una columna fuerte al mando del comandante Vilanova [José Vilanova Salcedo]. Os contaré detalles. Adiós $^{46}$.

El comandante de Artillería José Vilanova creó una columna muy heterogénea el 21 de agosto. Sus fuerzas eran una compañía de Ingenieros, una batería y secciones de morteros, ametralladoras, Infantería e Intendencia. Su papel fue clave el día 22 en las fincas de Son Vives y Son Sureda para detener la ofensiva de los republicanos hacia Sant Llorenç. Allí, aprovechando que dominaba el pueblo desde la altura, la columna de Gafim cortó el avance de Bayo ${ }^{47}$.

Durante el 22 de agosto llegaron siete hidros republicanos que recuperaron momentáneamente el control del cielo. Uno de los aviones italianos fue inutilizado y los otros dos volvieron a Italia. En los días siguientes, la batalla más encarnizada se libraría al norte, en los municipios de Son Servera y Sant Llorenç, justo donde operaba Gafim ${ }^{48}$.

Carta a su novia el 24 de agosto de 1936 (Ses Toltes-Son Sureda, frente de Sant Llorenç)

Esta vida azarosa y llena de aventuras me gusta horrores, hasta he engordado algo desde que estoy por aquí. Hace dos días que estoy en la línea de fuego y noto (;horror!) que esta vida empieza a gustarme. Seguramente los hombres llevamos escondidos instintos de bestia salvaje. (...) Estamos entre Son Servera y Son Carrió y vamos batiendo al enemigo que era más numeroso de lo que creían algunos. Digo era porque lo vamos batiendo en todos sus frentes. (...) Biel.

Carta a sus padres el 24 de agosto de 1936 (Ses Toltes-Son Sureda, frente de Sant Llorenç)

Esto de la guerra es terrible para unos, no tan terrible para otros, indiferente para unos pocos (...). Los frentes se van organizando y el enemigo pierde posiciones de día en día (...); nada de guerrillas ahora, sino conquistar posiciones, fortificarlas $(\ldots)^{49}$.

Este día 24 de agosto la columna de Gafim lanzó una ofensiva contra la finca de Can Pocafarina pero fueron repelidos ${ }^{50}$. A partir de ahí, recibieron orden de mantenerse a la defensiva. En la carta que le envió a su novia había un pequeño papel con una orden firmada por su comandante, José Vilanova. Decía lo siguiente: "Misión defenderse. Lo que pasa es que vamos a tomar Son (sic) Poca Farina y paquean ${ }^{51}$ a nuestra gente".

Carta a sus padres el 25 de agosto de 1936 (Son Vives, frente de Sant Llorenç)

He hecho un gran papel con mis morteros (...). Esto acabará pronto, el enemigo no existe más que embarcado, nunca sale de casa. Estoy de $2^{\circ}$ jefe de la posición de Son Vives en la carretera de San Lorenzo a Son Servera (a la derecha) es inexpug- 
nable y está muy bien fortificada. Desde aquí batimos con mis morteros una extensa zona. (...) Biel.

Este mismo día 25, el comandante Bayo pidió más medios al Gobierno debido a los ataques enemigos y citó expresamente los morteros: "Nos tiran numerosos cañones, morteros y mortalidad ametralladora". Durante esta jornada, la columna de Gafim ocupó la finca de Rafal Sec en Sant Llorenç, a 500 metros al noroeste de Son Carrió. Esta posición era "muy incómoda" porque los republicanos les cañoneaban desde el Puig de Ses Talaies.

El 26 de agosto las fuerzas de Bayo tomaron Son Carrió y, el Puig de Son Manxo. la columna de Gafim se vio obligada a abandonar la finca de Rafal Sec y retroceder. Esta operación abrió un boquete muy peligroso en el centro de la línea nacional pero Bayo no supo aprovecharlo. La tropa republicana no avanzó más. Su moral decaía por la falta de material. Les habían prometido más aviones, tanques y artillería. Llegaron a construir un aeródromo para unos cazas que nunca llegaron. Al día siguiente, la columna de Gafim avanzó y tomó Can Pocafarina ${ }^{52}$.

Carta a su novia el 28 de agosto de 1936 (Son Vives, frente de Sant Llorenç)

Hace sólo tres días que como caliente desde que estoy en la línea de fuego. Ahora me ... [ininteligible], a los conejos, palomas, pollos, patos, cerdos y todo lo que encontramos. Mi estómago funciona como nunca hubiera funcionado. (...) Me siento envejecido. Aqui se vive muy deprisa y muy intensamente. (...). No es verdad que sean 2.000 ni mucho menos, lo que pasa es que están muy bien colocados y atrincherados en más lomas y desde allí hostilizan y molestan bastante. Juro que les iremos sacando de la madriguera. (...) Biel.

Carta a sus padres el 28 de agosto de 1936 (Son Vives, frente de Sant Llorenç)

(...) Creo que mañana se prepara una operación de cierta envergadura (...). Esto [de la guerra] endurece el corazón al más sensible de los hombres (...).

El día 28 se mantuvieron las posiciones por ambas partes. Sólo hubo una pequeña escaramuza en la línea de Sant Llorenç, cerca de la posición de Gafim, en la que resultó muerto un falangista y varios republicanos. Este día llegaron tres cazas italianos Fiat-CR.32 y tres hidros Macchi-41 que a media mañana inutilizaron tres hidros republicanos y pusieron en fuga a varios barcos de transporte ${ }^{53}$. Gafim da cuenta de ello en la siguiente carta.

Carta a su novia el 29 de agosto de 1936 (Son Vives, frente de Sant Llorenç)

Querida mía: te escribo encima de una caja de municiones oyendo cómo algunas balas enemigas silban por encima del parapeto. (...) De lo único que me quejo es de la falta de dormir. Dormimos poco. En cuanto a comer, comemos mucho y bien por estas fincas hay víveres en abundancia. Ayer hicieron aparición nuestros aviones de caza. Desde entonces, no hemos visto a ningún aparato enemigo y parece que la 
canalla invasora les tiene un miedo atroz pues desde ayer por la tarde hay bastante tranquilidad.

(...) En Manacor hay la mar de gente que está todo el día rascándose la barriga, principalmente falangistas a los cuales he visto huir como conejos en más de dos ocasiones. Hace una semana que estoy en la línea de fuego y aguantando mecha mientras los otros van y vienen contando hazañas y tonterías, la mayor parte inventadas. (...) Biel.

Durante el 29 de agosto la aviación italiana continuó machacando la retaguardia republicana y causó gran desmoralización en el enemigo. Las fuerzas nacionales se organizaron en cinco agrupaciones de unos 500 hombres cada una (unos 2.600 en total). La de Gafim seguía comandada por José Vilanova y se extendía desde el sur de la finca Son Sureda hasta el sur de Can Pocafarina. Sin embargo, a él lo trasladaron este día a la primera agrupación que comandaba Enrique Esquivias y se desplegaba en todo el área sur del frente: desde Sa Carrotja hasta Porto Cristo. Este día llegó a Palma Arconovaldo Bonacorsi, más conocido como el "conde Rossi"

En cuanto a las desbandadas de falangistas que cita, puede referirse a la que ocurrió el 26 de agosto en Son Carrió. Massot afirma que en ese pueblo "se produjeron escenas de pánico e insubordinación” con soldados huyendo hacia Manacor. Gafim estaba en aquel momento en la finca del Rafal Sec, zona alta colindante a Son Carrió por el norte, así que pudo haber divisado la huida ${ }^{55}$.

\section{Carta a su novia el 31 de agosto de 1936 (Porto Cristo)}

Desde anteayer estoy en Porto Cristo arreando pepinazos al enemigo que, aunque poco numeroso, está bien fortificado y parapetado y es muy difícil sacarle de sus madrigueras. Nuestra aviación está realizando una labor magnífica. El enemigo está desmoralizado y resiste sólo por instinto de conservación y no como antes por afán de conquista. Todo lo que te digo es de verdad, a ti te lo puedo decir porque sé que te lo tomas con serenidad.

La columna que opera aquí es la del comandante [Enrique] Esquivias [Zurita] de Infantería. (...) La calidad de mis morteros es formidable. En estos dos días he causado yo solo más de treinta bajas al enemigo sin contar con el efecto moral que es considerable. (...). Creo que dentro de tres o cuatro días lo de Porto Cristo se terminará y entonces es probable que nos veamos en Manacor. (...) Biel.

En efecto, la acción de los morteros fue devastadora en Can Servera, la zona alta de Porto Cristo conocida como el "parapeto de la muerte". Bayo reconoce que esa posición costaba entre ocho y diez muertos diarios y que el mortero de campaña "batió en Mallorca grandes records de sangre". A pesar de ello, los republicanos no retrocedieron.

El 2 de septiembre llegaron de Italia tres nuevos bombarderos Savoia-81 y los nacionales avanzaron por el norte con la conquista del Puig de Son Corb, en Son Servera. Al día siguiente, llegaron a aguas de Punta Amer el acorazado Jaime I y el crucero Libertad con la misión de proteger el reembarque de los republicanos. Bayo 
utilizó una artimaña para no general un caos: mentir a los milicianos diciéndoles que debían trasladarse en los barcos a Palma porque la ciudad se había rendido. El reembarque se hizo de noche y con cierta disciplina. Los nacionales no reaccionaron porque pensaban que los republicanos estaban recibiendo más refuerzos ${ }^{56}$.

\section{Carta a sus padres el 3 de septiembre de 1936 (Manacor)}

No sabéis la ilusión que hace recibir correspondencia cuando se está en el frente. En eso coinciden todos los escritores de cosas de guerra. Ahora veo que es sencillamente criminal no escribir a un soldado que lucha en la línea de fuego. iSi supieran como se agradece cada línea que se escribe!

Los nacionales se dieron cuenta de la retirada republicana la noche del 3 al 4 de septiembre y comenzaron a avanzar. El último día de la batalla, el día 4, fue un paseo militar con algún tiroteo esporádico. La Agrupación Esquivias, donde estaba Gafim, tomó sin apenas lucha Can Servera y el "parapeto de la muerte". También entró ese día en Porto Cristo el "Conde Rossi" con sus falangistas y apresaron a varios milicianos que no pudieron huir. A pesar de ello, la evacuación republicana fue, en términos generales, un éxito. El Marqués de Comillas llevó 3.000 combatientes a Barcelona y el buque Mar Negro unos 4.000 a Valencia ${ }^{57}$.

Las cifras de víctimas no están claras. Todavía no existe un estudio científico al respecto. Massot dice que las cifras más fiables son las de la Historia de la Cruzada, que habla de "1.700 bajas entre muertos y heridos"

La República no volvería a intentar retomar la isla y dejó que se convirtiera en un gran portaviones desde donde hostigar todo el levante peninsular. La aviación italiana realizó más de 3.000 bombardeos causando miles de víctimas en Barcelona, Valencia, Alicante, etc. Además, derribaron 54 aviones y acosaron a la marina republicana en todo el Mediterráneo.

\section{Después de la batalla}

Después del combate de Manacor, Gafim ascendió a teniente y fue destinado a los cañones de la costa nordeste para vigilar la Menorca republicana. La siguiente carta ya la envió desde Artà el 10 de septiembre y en ella explica que los oficiales estaban muy bien instalados y sólo se distraían con instrucción en la montaña y la costa ${ }^{59}$. Gafim pasó el resto de la guerra relativamente tranquilo en Mallorca y el 19 de abril de 1938 se casó con Maria Antònia Sureda Sancho. Él tenía 25 y ella 23. Vivieron los primeros años en la Colonia de Sant Pere (Artà) y después en Palma. Tuvieron tres hijos.

Falleció de un infarto mientras leía un libro el 19 de enero de 1977. Tenía 64 años. El funeral fue masivo y todos los periódicos de la isla le rindieron homenaje desde sus páginas ${ }^{60}$. El 31 de marzo de 1979, el Ayuntamiento de Palma inauguró un busto 
de Gafim en una de las columnas principales de la Plaza Mayor. Bajo él, una simple inscripción: "Gabriel Fuster Mayans 'Gafim', 1913-1977”.

\section{Conclusiones}

Los datos de las cartas de Gafim a su novia se ajustan a la realidad en una época de profunda falta de información y manipulación por parte de la prensa y las autoridades. Las crónicas que recibió María Antonia Sureda Sancho fueron de gran valor en aquel momento: eran muy exactas porque fechas y hechos coinciden con los actuales trabajos científicos basados en multitud de fuentes. Así lo demuestra el cotejo con trabajos reconocidos por la comunidad académica como son los de Massot i Muntaner, el cual no pudo consultar estas misivas, así que, en realidad, se refrendan mutuamente. Por todo ello, las 18 cartas hasta ahora inéditas de Gabriel Fuster Mayans constituyen un testimonio imprescindible para conocer de primera mano qué ocurrió en Mallorca los primeros meses de la guerra.

Respecto a la batalla, según sus palabras, la organización de la defensa de la isla fue brillante. El propio comandante Bayo destaca el papel de los morteros y la artillería nacional, arma donde sirvió el periodista. A pesar de un desembarco masivo, Gafim nunca dudó de las posibilidades de victoria del bando nacional. Se adaptó de manera sorprendente a la vida entre las balas y su moral fue en aumento a medida que pasaba más tiempo en el frente. Sus intervenciones con los morteros se contaban por victorias. Los primeros días fueron claves. Su unidad mantuvo la línea de defensa de la Cuevas dels Hams y evitó la conquista de Sant Llorenç. Después, consiguió tomar Can Pocafarina e hizo un buen papel en Porto Cristo. Sólo retrocedió una vez, el 26 de agosto, cuando los republicanos tomaron Son Carrió y su columna abandonó la finca de Rafal Sec, situada al norte del pueblo.

Nunca supo de manera precisa a cuántos enemigos se enfrentaba. Pensaba que era menos numeroso y dice de él que estaba bien atrincherado y sabía resistir. El apoyo de la aviación italiana fue decisivo en el transcurso de la batalla, tanto que su mera intervención se entendía como una inminente victoria final. Sobre todo la llegada de cazas y bombarderos el 27 de agosto.

El resto de la guerra lo pasó en labores de vigilancia y defensa de costa. El conflicto marcó a Gafim para toda su vida porque le introdujo en la ideología imperante en el momento: el fascismo. Recibió honores de excombatiente y en 1943 ingresó en Falange. Su adhesión por el Movimiento Nacional fue in crescendo hasta llegar a ser reconocido como miembro de la Vieja Guardia. De hecho, su labor periodística se desarrolló en el diario del movimiento, Baleares, durante 40 años. Socías señala que la guerra le aportó fama como excombatiente y le facilitó el acceso a la élite de escritores y periodistas del franquismo ${ }^{61}$. El resto lo hizo su pluma. Con ella se ganó la admiración de sus compañeros, el respeto de los palmesanos y un hueco en la Historia. 


\section{Referencias bibliográficas}

ARROM, S. (1989). "Correspondència de Bartomeu Rosselló-Pòrcel: Set cartes a Gabriel Fuster Mayans (Gafim)”. En Estudis Baleàrics, núm. 32. Palma: Conselleria de Educació i Cultura.

BAYO, A. (2010). Mi desembarco en Mallorca. Palma: Miquel Font.

BRAUNSTEIN, B. (1976): Els xuetes de Mallorca. Barcelona: Curiel.

BUADES JUAN, J. (1997). "El paper dels intel.lectuals mallorquins en la difusió de la ideologia franquista". En Butlletí de la Societat Arqueológica Lul.liana, 53, 353-368.

CRUELLS, M. (1971). L'expedició a Mallorca, any 1936. Barcelona: Juventud.

DURÁN, M. (1982). 1936 en Mallorca. Palma: Imagen.

FERRÀ-PONÇ, D. (2006). Cultura i política a Mallorca. Palma: Diari de Balears.

MARÍN LLADÓ, C. (1999). Gabriel Fuster Mayans (Gafim). Un periodista en la Mallorca franquista. Palma: Lleonard Muntaner.

"Correspondència de Bartomeu Rosselló-Porcel i Salvador Espriu: cartes i postals dels poetes al periodista Gabriel Fuster Mayans, Gafim". En Estudis Baleàrics, núm. 64-65 (se publicaron juntos). Palma: Conselleria de Educació i Cultura.

MARTÍNEZ BANDE, J. M. (1989). La invasión de Aragón y el desembarco en Mallorca. Madrid: San Martín.

MASCARÓ PASARIUS, J. (1975). "El movimiento nacional en Mallorca". En MASCARÓ PASARIUS (Dir.). Historia de Mallorca. Tomo II. Palma: Mascaró Pasarius.

MASSOT I MUNTANER, J. (1978). Cultura i vida a Mallorca entre la guerra i la posguerra (1930-1950). Barcelona: Abadia de Montserrat.

(1987). El desembarcament de Bayo a Mallorca. Barcelona: Abadia de Montserrat.

(1988). Vida i miracles del 'Conde Rossi'. Barcelona: Abadia de Montserrat. (1998). Els bombardeigs de Mallorca durant la Guerra Civil (1936-1938). Barcelona: Abadia de Montserrat.

SABATER, G. (2014). "La Palma de Gafim”. En El Mundo / El Día de Baleares, 1 de septiembre de 2014, pág. 6 .

SOCÍAS COLOMAR, M. (2008). Cartes de posguerra: de Miquel Villalonga a Gafim. Binnisalem: Fundació Casa Museu Llorenç Villalonga.

TUGORES, A. (2006) Manacor, la guerra a casa. Palma: Documenta balear. (2013) Com la carn de xinxa. Palma: Lleonard Muntaner.

Webgrafía

"Biografía de Emilio Ramos Unamuno", Gran Enciclopèdia de Mallorca, vol. 14, pág. 194. En http://www.fideus.com/biografiesF\%20-\%20ramos\%20unamuno\%20 -\%20emilio.htm [octubre 2014]

AMER BALLESTER, C.: "Gabriel Fuster Mayans". En Diccionari de Periodisme de les Illes Balears. Grup d'Estudi de la Cultura, la Societat i la Política al 
Món Contemporani de la UIB. En http://diccionariperiodisme.wikispaces.com/ Gabriel+Fuster+Mayans [septiembre 2014]

\section{Prensa citada}

Arriba (Manacor), 27-8-1938.

DiariodeMallorca,15-3-2012.Enhttp:/www.diariodemallorca.es/mallorca/2012/03/15/ documentan-playa-sa-coma-fosa-comun-500-victimas-franquismo/752313.html [diciembre 2014]

El Día, 5-8-1936.

El Mundo / El Día de Baleares, 1-9-2014, pág. 6.

La Almudaina, 5-8-1936, pág. 1; y 11-8-1936, pág. 2.

Última Hora, 5-1-2015. http:/ultimahora.es/sucesos/ultimas/2015/01/05/141366/armada-guardia-civil-desactivan-granada-mortero-frente-cala-gamba.html [5 de enero de 2015]

\section{Notas}

1 Obra de Remígia Caubet.

2 Carta de Gabriel Fuster a Maria Antònia Sureda del 31 de agosto de 1936. Estas misivas están en una colección privada cuyo propietario quiere quedar en anonimato. No obstante, los investigadores pueden contactar con el autor de este artículo para que medie para su consulta.

3 Las cartas de Rosselló-Pòrcel son de los años universitarios y tratan solo temas triviales. ARROM, S. (1989). "Correspondència de Bartomeu Rosselló-Pòrcel: Set cartes a Gabriel Fuster Mayans (Gafim)". En Estudis Baleàrics, núm. 32. Palma: Conselleria de Educació i Cultura. Págs. 43-6; MARÍN LLADÓ, C. (1999). "Correspondència de Bartomeu Rosselló-Porcel i Salvador Espriu: cartes i postals dels poetes al periodista Gabriel Fuster Mayans, Gafim”. En Estudis Baleàrics, núm. 64-65 (se publicaron juntos). Palma: Conselleria de Educació i Cultura. Págs. 37-46; y SOCÍAS COLOMAR, M. (2008). Cartes de posguerra: de Miquel Villalonga a Gafim. Binnisalem: Fundació Casa Museu Llorenç Villalonga.

4 MARÍN LLADÓ, C. (1999). Gabriel Fuster Mayans (Gafim). Un periodista en la Mallorca franquista. Palma: Lleonard Muntaner. Págs. 11-2; Sobre los xuetes hay mucho trabajo científico. Véase por ejemplo BRAUNSTEIN, B. (1976): Els xuetes de Mallorca. Barcelona: Curiel.

5 ARROM, S. (1989) Op. cit. pág. 43; También fue obligado a estudiar Derecho por una tradición familiar de cinco generaciones. MARÍN LLADÓ, C. (1999). "Correspondència... pág. 37-8.

6 Ibid Pág. 25.

7 MARÍN LLADÓ, C. (1999). Gabriel Fuster... Págs. $42-5$.

8 MASSOT I MUNTANER, J. (1978). Cultura i vida a Mallorca entre la guerra i la posguerra (19301950). Barcelona: Abadia de Montserrat. Pág. 263n.

9 BUADES JUAN, J. (1997). "El paper dels intel.lectuals mallorquins en la difusió de la ideologia franquista". En Butlletí de la Societat Arqueológica Lul.liana, 53, 353-368. Pág. 356.

10 En su cuento "El dimoni de Vallvidrera" (1955). Citado en MARÍN LLADÓ, C. (1999): "Correspondència... Págs. 38-9; FERRÀ-PONÇ, D. (2006). Cultura i política a Mallorca. Palma: Diari de 
Balears; AMER BALLESTER, C.: "Gabriel Fuster Mayans". En Diccionari de Periodisme de les Illes Balears. Grup d'Estudi de la Cultura, la Societat i la Política al Món Contemporani de la UIB. En http://diccionariperiodisme.wikispaces.com/Gabriel+Fuster+Mayans [septiembre 2014]

11 BUADES JUAN, J. (1997). Op. cit. pág. 357; y AMER BALLESTER, C. Op. cit.

12 MARÍN LLADÓ, C. (1999). Gabriel Fuster... Pág. 49.

13 Ibid Págs. 69-70.

14 SABATER, G. (2014). “La Palma de Gafim”. En El Mundo / El Día de Baleares, 1-9-2014, pág. 6.

15 MASSOT i MUNTANER, J. (1987). El desembarcament de Bayo a Mallorca. Barcelona: Abadia de Montserrat. Págs. 34-38; MASCARÓ PASARIUS, J. (1975). "El movimiento nacional en Mallorca". En MASCARÓ PASARIUS (Dir.). Historia de Mallorca. Tomo II. Palma: Mascaró Pasarius. Págs. 789-791.

16 Carta de Gafim a Maria Antònia Sureda del 28 de julio de 1936.

17 MASSOT i MUNTANER, J. (1998): Els bombardeigs de Mallorca durant la Guerra Civil (19361938). Barcelona: Abadia de Montserrat; MASCARÓ PASARIUS, J. (1975). Op. cit. págs. 792-3.

18 Carta a Maria Antònia Sureda del 4 de agosto de 1936.

19 MASSOT MUNTANER, J. (1987). Op. cit. Pág. 78, 86 y 396; "Diario de una miliciana", Arriba (Manacor), 27-8-1938; MARTÍNEZ BANDE, J. M. (1989). La invasión de Aragón y el desembarco en Mallorca. Madrid: San Martín. Pág. 150; DURÁN, M. (1982). 1936 en Mallorca. Palma: Imagen. Vol. III. Pág. 538. Citado en MASSOT MUNTANER, J. (1987). Op. cit. Pág. 157.

20 Dos días antes, el 21 de julio, había habido un pequeño ataque en la playa de Pollença. MASSOT i MUNTANER, J. (1998). Els bombardeigs... Pág. 11.

21 Ibid Pág. 12-3.

22 Ibid Pág. 14-5; MASCARÓ PASARIUS, J. (1975). Op. cit. Pág. 792.

23 MASSOT i MUNTANER, J. (1998). Op. cit. Pág. 17.

24 Ibid Pág. 16-7.

25 MASSOT MUNTANER, J. (1987). Op. cit. Pág. 46.

26 MASSOT i MUNTANER, J. (1998). Op. cit. Pág. 18-20.

27 Ibid Pág. 23-24; MASCARÓ PASARIUS, J. (1975). Op. cit. Págs. 797-8.

28 BAYO, A. (2010). Mi desembarco en Mallorca. Palma: Miquel Font. Págs. 58-60.

29 MASSOT i MUNTANER, J. (1998). Op. cit. Pág. 28; BAYO, A. (2010). Op. cit. Pág. 59.

30 La Almudaina, 5-8-1936, pág. 1; MASSOT i MUNTANER, J. (1998). Op. cit. Pág. 25; El Día, 5 de agosto de 1936. En MASCARÓ PASARIUS, J. (1975). Op. cit. Pág. 797; Lamentablemente, el archivo de La Almudaina no guarda ninguno de estos ejemplares apócrifos. El archivo está en la sede del Diario de Mallorca, en la calle Puerto Rico, 15, de Palma.

31 MASSOT MUNTANER, J. (1987). Op. cit. Pág. 159-160; MARTÍNEZ BANDE, J. M. (1989). Op. cit. Pág. 161; MASCARÓ PASARIUS, J. (1975). Op. cit. Pág. 798.

32 DURÁN, M. (1982). Op. cit. Pág. 429. Citado En MASSOT i MUNTANER, J. (1987). Op. cit. Pág. 159 n.

33 MARTÍNEZ BANDE, J. M. (1989). Op. cit. Pág. 159-160; MASSOT i MUNTANER, J. (1987). Op. cit. Pág. 164. 
34 "Biografía de Emilio Ramos Unamuno", Gran Enciclopèdia de Mallorca, vol. 14, pág. 194. En http:// www.fideus.com/biografiesF\%20-\%20ramos\%20unamuno\%20-\%20emilio.htm [octubre 2014]

35 La Almudaina, 11-8-1936, pág. 2.

36 MARÍN LLADÓ, C. (1999). Gabriel Fuster... págs. 39-40.

37 BAYO, A. (2010). Op. cit. Pág. 60.

38 MASSOT i MUNTANER, J. (1987). Op. cit. Pág. 161.

39 El 5 de enero de 2015 un pescador encontró frente a Torre d'en Pau una granada de mortero a pocos metros de profundidad. La Guardia Civil confirmó que era de la guerra civil y la explosionó. Allí no hubo combates, así que casi con toda seguridad procedía de aquellas prácticas que realizó Gafim. Última Hora, 5-1-2015. http://ultimahora.es/sucesos/ultimas/2015/01/05/141366/armada-guardia-civil-desactivan-granada-mortero-frente-cala-gamba.html [5 de enero de 2015]

40 MASSOT i MUNTANER, J. (1998). Op. cit. Págs. 32, 32n y 33.

41 Ibid Pág. 32-3; MASCARÓ PASARIUS, J. (1975). Op. cit. Pág. 798.

42 MASCARÓ PASARIUS, J. (1975). Op. cit. Págs. 836 y 838; BAYO, A. (2010). Op. cit. Pág. 98.

43 Es posible que algunos anarquistas de Cabrera lo confundieran con Porto Cristo y tras ver el error reembarcaran de nuevo.

44 MARTÍNEZ BANDE, J. M. (1989). Op. cit. Págs. 176-8 y 182; CRUELLS, M. (1971). L'expedició a Mallorca, any 1936. Barcelona: Juventud. Pág. 69.

45 MARTíNEZ BANDE, J. M. (1989). Op. cit. Pág. 187; MASCARÓ PASARIUS, J. (1975). Op. cit. Pág. 843.

46 MARÍN LLADÓ, C. (1999). Op. cit. pág. 39.

$47 \mathrm{Al}$ inicio de la guerra, el comandante Vilanova había dirigido la columna que se envió a Manacor para tomar el Ayuntamiento, el cual mantenía la legalidad republicana. Después sería nombrado jefe de la Falange de Manacor. MASSOT i MUNTANER, J. (1987). Op. cit. Pág. 42; CRUELLS, M. (1971). Op. cit. Pág. 84; TUGORES, A. (2006). Manacor... Pág. 288; y (2013) Com la carn de xinxa. Palma: Lleonard Muntaner. Págs. 19-20 y 39.

48 MASSOT i MUNTANER, J. (1987). Op. cit. Pág. 212; MARTíNEZ BANDE, J. M. (1989). Op. cit. Pág. 188; CRUELLS, M. (1971). Op. cit. Pág. 83.

49 MARÍN LLADÓ, C. (1999). Op. cit. Pág. 39.

50 MARTÍNEZ BANDE, J. M. (1989). Op. cit. Pág. 191.

51 "Paquear" significa disparar de manera aislada. La causa es el sonido de las balas aisladas: "Pacoooun".

52 MASCARÓ PASARIUS, J. (1975). Op. cit. Pág. 846; MARTÍNEZ BANDE, J. M. (1989). Op. cit. Pág. 192-3; BAYO, A. (2010). Op. cit. Pág. 119; CRUELLS, M. (1971). Op. cit. Pág. 85; Muchos dirigentes republicanos, entre ellos Indalecio Prieto, no creían en la operación sobre Mallorca y pensaban que ese material era más útil en los frentes de la península. Así lo manifestó en un artículo en el diario Informaciones el 27 de agosto de 1936. Bayo lo calificó como "un bombardeo más terrible que el de los italianos". BAYO, A. (2010). Op. cit. Pág. 127.

53 MASSOT MUNTANER, J. (1987). Op. cit. Pág. 264-5; MARTÍNEZ BANDE, J. M. (1989). Op. cit. Pág. 194-6. 
54 TUGORES, A. (2006). Manacor, la guerra a casa. Palma: Documenta balear. Pág. 149; Había llegado en hidroavión tres días antes a Pollença. En MASSOT I MUNTANER, J. (1988). Vida $i$ miracles del 'Conde Rossi'. Barcelona: Abadia de Montserrat. Pág. 49.

55 MASSOT MUNTANER, J. (1987). Op. cit. Pág. 213; MASCARÓ PASARIUS, J. (1975). Op. cit. Pág. 848.

56 MASSOT MUNTANER, J. (1987). Op. cit. Págs. 274-5 y 332n; MARTÍNEZ BANDE, J. M. (1989). Op. cit. Págs. 204-6.

57 MARTÍNEZ BANDE, J. M. (1989). Op. cit. Pág. 207-8.

58 En el botín había 4 hidroaviones, 2.709 fusiles, 24 ametralladoras, 1.638 granadas de mano, 13.471 kilos de patatas, etc. La Asociación para la Recuperación de la Memoria Histórica de Mallorca asegura que en la playa de Sa Coma, en Sant Llorenç, hay 500 cuerpos enterrados, los cuales pertenecerían a las fuerzas de Bayo. MASSOT MUNTANER, J. (1987). Op. cit. Pág. 324-6 y 327-332; Diario de Mallorca, 15-3-2012. En http://www.diariodemallorca.es/mallorca/2012/03/15/documentan-playa-sa-coma-fosa-comun-500-victimas-franquismo/752313.html [diciembre 2014]

59 Carta de Gafim a Maria Antònia Sureda del 10 de septiembre de 1936.

60 Marín recoge extractos de varios de los artículos que le dedicaron. MARÍN LLADÓ, C. (1999). Op. cit. Págs. 87-90.

61 SOCÍAS COLOMAR, M. (2008). Cartes de posguerra... Pág. 9. 